\title{
The Textual Standardization of Midwives' Professional Relationships ${ }^{1}$
}

\author{
Philippa Spoel and Susan James
}

Cet article développe une analyse rhétorique d'un choix des documents produits par le Collège des sages-femmes de l'Ontario pour réglementer la profession de sage femme. Nous y explorons les tensions contextuelles-textuelles adressées et inscrites par le méta-genre "CMO " en nous concentrant sur les incongruités rhétoriques et les valeurs en concurrence relativement à trois des normes qui réglementent les rapports professionnels des sages-femmes, soit: 1) la philosophie des soins offerts par les sages-femmes en Ontario, 2) la continuité des soins, et, 3) les approches indiquées relativernent à la discussion, la consultation et le transfert obligatoires des soins. Notre analyse des écrans terministiques mixtes et incongrus présents dans l'énoncé de ces normes révèle les tensions idéologiques et pratiques principales qui informent la négociation rhétorique dans laquelle les sages-femmes sont engagées dans le contexte de leur nouveau et difficile statut à l'intérieur du système dominant des soins de la santé. Simultanément, ce processus de négociation met en premier plan et modifie, de façons hétérogènes, le rapport de confiance intime et central entre les sages-femmes et les femmes dont elles ont soin qui, avant la réglementation, constituait une valeur fondamentale de la profession de sage-femme.

This article develops a rhetorical analysis of a selection of documents produced by the College of Midwives of Ontario for regulating the profession of midwifery. We explore the contextual-textual tensions addressed and inscribed by the CMO meta-genre by focusing on the rhetorical incongruities and competing values in three standards that regulate midwives' professional relationships: 1) Philosophy of Midwifery Care in Ontario, 2) Continuity of Care, and 3) Indications for Mandatory Discussion, Consultation and Transfer of Care. Our analysis of the mixed, incongruous terministic screens in these standards reveals key ideological and practical tensions that inform midwifery's rhetorical negotiation of its new and uneasy status within the dominant healthcare system. This negotiation process at once foregrounds and 
reconfigures, in heterogeneous ways, the central, intimate relationship of trust between midwives and the women for whom they care that constitutes a fundamental value of pre-regulation midwifery.

\section{Standard:}

A flag, sculptured figure, or other conspicuous object, raised on a pole to indicate the rallying point of an army...; the distinctive ensign of a king, great noble, or of a nation or city.... the centre from which commands are issued.

The authorized exemplar of a unit of measure or weight; e.g. a measuring rod of unit length; a vessel of unit capacity, or a mass of metal of unit weight, preserved in the custody of public officers as a permanent evidence of the legally prescribed magnitude of the unit.

Of a book, an author: That has a permanent rank as an authority, or an examplar of excellence.

Of a law: That has the chief authority with reference to a particular subject.

Oxford English Dictionary

\section{Introduction}

Since the late nineteenth century, childbirth practices in Canada have been controlled almost exclusively by the medical profession with virtually no official role for midwives in the maternity care system. Until very recently, midwives have been forced to practice outside the system, placing them "at best in a legal limbo, at worst liable to prosecution" (Barrington, 1984, p. 7). During the past decade, however, midwifery has begun to secure status as a legally-recognized, self-regulated health profession in several provinces. ${ }^{2}$ Although Ontario midwives and their supporters were not the first in Canada to begin the arduous lobbying process for midwifery to become a selfregulated profession, Ontario was the first province to grant midwifery this status as part of the province's comprehensive Health Professions Legislative Review conducted during the 1980s and early 1990s. Through its 1991 Midwifery Act, Ontario included midwifery as one of the province's self-regulated and provincially-funded health professions, with the concomitant requirement to establish a College of Midwives of Ontario as the governing body for the profession. Led by a Council composed of 
approximately two-thirds members of the profession and one-third members of the public, the CMO's primary duty, according to Ontario's Health Professions Procedural Code, is to "serve and protect the public interest" by establishing and maintaining standards of qualification, practice, knowledge, skill, and professional ethics for midwives (Ontario Regulated Health Professions Act, 1991, p. 23). To fulfill this mandate, the $\mathrm{CMO}$ has produced and continues to produce numerous regulatory documents for governing the emerging profession of midwifery. Although the general types of documents that the CMO produces conform to government determined categories (such as by-laws, regulations, policies, and standards), the specific documents within each of these generic categories are developed intra-professionally by the College. This tension between the role of government and the role of the profession in composing midwifery's regulatory texts reflects, as David Coburn points out, how under Ontario's new Regulated Health Professions Act, Colleges became "not simply professional organizations designed to self-regulate the profession by members of the profession itself, but, with reduced powers, part of a system of organizations, all with lay input and responsive to quasi-state influence if not direct control" (136).

In our view, the CMO regulatory documents constitute an important genre of professional discourse worth examining from a rhetorical perspective so that we can better understand some of the implications of self-regulation for midwives and for the women and families who choose midwifery care. Our purpose in undertaking this study is not to criticize or undermine the profession of midwifery, but to contribute to a deeper appreciation of how it rhetorically negotiates its complex, ambivalent situation within the healthcare system. For midwifery-a self-proclaimed alternative, women-centred, holistic form of healthcare-professionalization within the mainstream, medically-dominated healthcare system constitutes an inherently problematic process informed by ideological struggles, competing values, and conflicts in standards. In this context, the CMO's evolving institutional discourse articulates standards that authoritatively define and shape the new profession of midwifery. However, the rhetorical incongruities within this institutional discourse at once reveal and contribute to the tensions that shape the identities and activities of midwives subject to the CMO standards.

\section{CMO Meta-Genre as a Site of Rhetorical-Ideological Conflict}

Collected together within a sub-sectioned, looseleaf binder entitled College of Midwives of Ontario-Registrant's Binder and distributed to midwives upon registration, the CMO regulatory documents constitute a particular, situated enactment of a broad genre legislated by the Ontario government for all self-regulated health professions through its Health Professions Legislative Review. As Bazerman (1994) notes, 
"the legal system and regulatory network of government organizes, institutionalizes, regulates, and creates compelling exigencies for the production and use of explicit characteristic genres in perhaps a more determined and articulate way than in other domains of life ..." (p. 80). In this sense, the production of the CMO regulatory texts occurs explicitly in response to the compelling exigencies of midwifery's new legal status within the larger healthcare system. In turn, the CMO texts articulate a compelling, authoritative framework that at once legitimates and constrains the professional practices of registered midwives. However, rather than being rhetorically stable and consistent, this authoritative framework is shaped by an ongoing process of adding, revising, and substituting specific components in light of diverse, shifting situational exigencies. Divided into a range of related yet distinct sub-genres ( including "Regulations," "Standards," "Policies," and "Guidelines"), the CMO binder both reflects and contributes to the complex, evolving, and uneasy trajectory of midwifery professionalization in Ontario.

As a whole, these regulatory texts function, we would argue, as a kind of metagenre set. According to Giltrow (2002), a "meta-genre" is "situated language about situated language." Meta-genres such as (institutional) guidelines can be both constraining and enabling, "ruling out certain kinds of expression, endorsing others" (pp. 190-191). While Giltrow employs the concept of meta-genre specifically in relation to the production of written genres, we find it a useful way to characterize the CMO regulatory texts: in our view, they function as a set of guidelines that both rule out and endorse diverse forms of professional activity for midwives, including but not limited to professional genres of communication. ${ }^{3}$ Meta-genres, Giltrow further argues, "implicate writers [or practitioners] in the struggles and conflicts of institutional systems" (p. 191) which, in the case of midwifery, inevitably involve value conflicts and ideological tensions. As Paré (2002) explains, “... ideology, as manifested in institutional practice, is fragmented and conflictual, ... with competing visions and values being advanced, challenged, negotiated, and altered. Genres are key institutional sites for such struggles" (p. 60). From this perspective, we are interested in exploring the CMO meta-genre as itself a contextually motivated site of ideological tensions which, through language, enacts some of political and philosophical conflicts that shape the emerging institutional system of midwifery self-regulation.

In this article, we explore the contextual-textual tensions addressed and inscribed by the $\mathrm{CMO}$ meta-genre by focusing on the rhetorical incongruities and competing values in three standards that regulate midwives' professional relationships: 1) Philosophy of Midwifery Care in Ontario, 2) Continuity of Care, and 3) Indications for Mandatory Discussion, Consultation and Transfer of Care (see Appendix A, B, and C). The Philosophy document focuses mainly on the relationship between the midwife 
and the client, the Continuity of Care text on the relationship between a midwife and other midwives, and the Indications document on the relationship between a midwife and physicians. Rhetorically speaking, these texts employ a mélange of what we refer to as quantitative and qualitative "terministic screens" (Burke, 1966) which, taken together, articulate potentially incongruous and competing views of the kinds of professional "realities" within which midwives and the women for whom they care are expected to function.

Our analysis of the terministic screens which these standards employ reveals key ideological and practical tensions at work within the CMO meta-discourse as the profession of midwifery negotiates its new and uneasy status within the dominant healthcare system. This process at once foregrounds and reconfigures, in heterogeneous ways, the central, intimate relationship of trust between midwives and the women for whom they care that constitutes a fundamental value of pre-regulation midwifery.

\section{Competing Terministic Screens: Biomedical Quantitative Discourse vs. Holistic Qualitative Discourse}

In her study of current discourses of interdisciplinary healthcare in Canada, Taylor (2001) explores how "the discourse of scientific medicine gives visible representation and voice only to that which can be quantified, rendering other, qualitative knowledges invisible and silenced" (p. 3). These two basic forms of knowledge, Taylor argues, reflect different conceptualizations of healthcare practice and of the human body: the dominant quantitative discourse of biomedicine conceptualizes an "object body ... which can be made visible, described, and manipulated." By contrast, qualitative research tends to conceptualize "the lived body": "the sum total of all experiences, the organic/sociocultural / psychological/spiritual self" (p. 4).

We find the basic distinction made by Taylor between primarily quantitative and primarily qualitative discourses useful for our own analysis of the three CMO standards, though we are not-as she has done-comparing texts from different domains of healthcare nor are we examining academic research texts. We use the terms "quantitative" and "qualitative" in a relatively broad rather than specialized academic sense to refer to what we see as two main rhetorical-epistemological tendencies within the CMO standards. Each of these tendencies functions, in Burke's terms, as a "terministic screen": a language or set of terms which constitutes a particular reflection of reality, a selection of reality, and a deflection of reality (1966, p. 45). In other words, the kind of reality articulated by a primarily quantitative terminology differs from (though does not necessarily oppose) the kind of reality represented by a primarily qualitative terminology. More specifically, by a "quantitative" terministic screen, we have in mind language that represents reality as uniform, measurable, replicable, comparable, ob- 
jectively known, and, therefore, standardizable. By discourse that is more "qualitative," we have in mind language that pictures the world or aspects of the world as variable, situated, irreducible, unique, subjectively known, and, therefore, perhaps non-standardizable.

From the point of view of the overall healthcare system and its legal, bureaucratic processes for regulating health professions and protecting the public, standards articulated principally in quantitative terms provide a kind of authoritative examplar or guideline of measurement that can be used both to structure and to assess midwifery practices in uniform, replicable, and comparable ways. However, from the point of view of midwifery as a distinct and alternative form of healthcare, standards that offer a more qualitative interpretation of reality function better to represent midwifery's own self-definition-that is, the terms in which it conceives itself and which, to some extent at least, challenge the medically-dominated forms of knowledge and practice in the main healthcare system. The interplay between these quantitative and qualitative terministic screens within the CMO standards reflects, we would argue, inevitable tensions within midwifery's trajectory of professionalization as it seeks to "maintain the model and philosophy of practice which emerged through a grassroots 'demand' for an alternative to the medical system of obstetrical care," while simultaneously cooperating with and securing insider status within the system that it has traditionally resisted (James, 1997, p.181). Of the three documents that we have selected for analysis, the Philosophy of Midwifery Care in Ontario provides the most strongly qualitative standard for the profession by describing the distinctive ideals of midwifery care in contrast to the dominant biomedical model. The Continuity of Care document likewise addresses a distinctive principle of the midwifery model of care, but it does so primarily through a quantitative explication of how midwives are to enact this principle in their professional practices together. The Indications document, for its part, defines three categories of interprofessional relationship between midwives and physicians and articulates in detail the particular medical conditions of childbearing women which require midwives to initiate these relationships.

\section{Philosophy of Midwifery Care: Articulating Midwifery's Distinctive Ideals for Caregiving}

A fundamental difference between traditional medical and midwifery perspectives on maternity care lies in their divergent views of the relationship between the caregiver and the person receiving care. By contrast with the transformation of birth by the medical profession "into a high technology procedure where the woman is merely a passive birthing vehicle" (Hughes, 1984, p. 2), midwifery fosters a womancentred approach to healthcare which is shaped by "feminist principles of sisterly 
connections based on mutual respect, effective kinship, and equality in relationships between women" (Sharpe, 1997, p. 233; see also Mason, 1990; James, 1997; Kitzinger, 1988). The CMO's Philosophy of Midwifery Care in Ontario provides, in our view, a kind of qualitative guideline for newly professionalized midwives to ensure that the ideal of the empathetic, non-authoritarian relationship between the midwife and the childbearing woman remains at the heart of midwifery care, despite the incorporation of midwifery within the dominant, medicalized healthcare system. For the most part, this document emphasizes the significant values and attitudes that differentiate midwifery care from standard (medicalized) healthcare. Paradoxically, however, it is precisely these distinctive values and attitudes which seem hardest to articulate in uniform, replicable, "objective" terms.

To illustrate how this standard articulates an inspirational but ambiguously specified guideline for holistic, women-centred midwifery care, we will discuss two of the ten statements in the Philosophy, beginning with the first (see Appendix A for full text):

Midwifery care is based on a respect for pregnancy as a state of health and childbirth as a normal physiologic process and a profound event in a woman's life.

This statement positions "respect" as a fundamental value or quality of midwifery care, both because it is named at the very beginning of the Philosophy and because it is described as the foundation for all of midwifery care. Interestingly, though, this statement does not identify respect primarily as an attitude held by one person for another (e.g., by the midwife for the childbearing women) but instead more impersonally and perhaps more ambiguously as an attitude held by all of midwifery care for all of pregnancy and childbirth. Further, although the Philosophyclearly announces that respect holds a central position within midwifery's self-conceptualization of its approach to healthcare, this passage does not provide concrete guidelines to members of the profession for what constitutes respect in practice. Indeed, as Perelman and Olbrechts-Tyteca (1971) suggest in their discussion of "universal values," the very persuasiveness of respect as a value-its ability to foster among members of the midwifery community a shared sense of the distinctive value of their approach to healthcare-may depend at least in part on its generality and lack of specified content (p. 76).

That the Philosophy is concerned with articulating the particular qualities of midwifery care as these contrast with a dominant biomedical approach to obstetrics is apparent not only from the foregrounding of the term respect, but from the choice 
of terms used to describe pregnancy and childbirth in the remainder of the sentence: identifying pregnancy as "a state of health" and childbirth as "a normal physiological process" implicitly contrasts the techno-medical representation of pregnancy and childbirth as "a pathological condition fraught with potential risk" (Massey, 1991, p. 7). Further, by characterizing childbirth as "a profound event in a woman's life," this opening statement of the Philosophy places the childbearing woman at the centre of midwifery care and recognizes the deep and unique impact of this experience on each woman who lives it. Childbirth is not, in this view, a uniform, replicable, quantitatively standardizable phenomenon but instead a multi-dimensional, non-comparable, life-altering event which the mother experiences with the support of midwives. Necessarily, such a "profound event" will be qualitatively different for each woman. Implicitly, this CMO standard argues that the role of midwifery care is to respect, not to seek to standardize, these qualitative differences.

The eighth statement in the "Philosophy" reads as follows:

Midwives promote decision-making as a shared responsibility, between the woman, her family (as defined by the woman) and her caregivers. The mother is recognized as the primary decision maker.

By describing decision-making as a "shared responsibility, between the woman, her family ... and her caregivers," this section of the Philosophy focuses on a central aspect of the relationship between the midwife and the childbearing woman. The midwife and the woman, along with the woman's family, are presented as working together cooperatively and equitably. The second sentence of this section, however, slightly reconfigures the concept of shared responsibility described in the first sentence; although the midwife and the mother share the responsibility for making decisions, ultimately it is the mother who has the role of "primary decision maker." Consonant with the feminist ideology of the women's health movement, this conceptualization of midwifery care presents an empowering vision of the childbearing woman as someone who takes responsibility and control over her life and health, as opposed to being "the passive object of the doctor's expertise, the physiological terrain on which the physician's work is performed" (Rushing, 1993, p. 92). At the same time, the shift from the concept of decision-making as a shared responsibility to the concept of the woman as primary decision-maker further reveals the difficulties of articulating in precise, unambiguous terms the abstract values that motivate the philosophy of midwifery care. 
Although the reference is not explicit, identifying the woman as primary decision-maker invokes the principle of informed choice which forms a central tenet of the Midwifery Model of Practice, contained in the "Policies" section of the CMO binder. ${ }^{4}$ This document explains that "[I] nformed choice is a decision-making process which relies on a full exchange of information in a non-urgent, non-authoritarian, co-operative setting" (p. 5). The concepts of informed choice ${ }^{5}$ and primary decision-making work hand in hand to construct a model of healthcare in which women and midwives exchange diverse forms of knowledge (including not only objective, scientific knowledge but also emotional, intuitive, spiritual, narrative, and other ways of knowing (James, 1997, p. 184) throughout the course of care as the basis for women taking responsibility for and control of their own healthcare. By contrast with the "technocratic" model of North American medical care in which, according to Davis-Floyd (1996), "not only are mother and baby viewed as separate but the best interests of each are often perceived as conflicting" (p. 266), midwifery's philosophy of care appears based on "a general trust that when the woman makes decisions for herself, those decisions are also good for her child. The mother is the 'expert' source of knowing what is good for self and child" (James, 1997, pp. 183-84).

However, for all that the CMO Philosophy endorses these fundamental values of midwifery care, it also provides an ambiguous, shifting explanation of the decisionmaking process from one of "shared responsibility" among the midwife, the woman, and the woman's family to one in which the mother commands principal authority. This ambiguity hints at the tension experienced by registered midwives between fulfilling their professional-legal responsibilities as regulated primary care providers within the terms of the dominant system, and giving over responsibility to women receiving care in accordance with midwifery's alternative, distinctive woman-centred model of care. As Sharpe (1997) explains based on her study conducted shortly after regulation, even though Ontario's self-regulated model specifies that "care is womancentred and that the woman makes the decisions based on informed choices," nonetheless the professionalization of midwifery restructures the nature of the relationship between the midwife and the woman: "With new educational and professional requirements, the midwives' knowledge base and education are becoming very different from that of their clients, and perhaps this sharing is evolving from one of a peer friendship in the past to one of a professional nature which may create boundaries" (Sharpe, 1997, p. 238).

Still, despite the ambiguities and tensions that we have noted, the CMO Philosophy in the main presents an ideal form of midwifery care that centres, both implicitly and explicitly, around the relationship between midwives and the women for whom they care. Integral to this representation are qualitative values and attitudes that would 
seem difficult to measure or standardize in uniform and unambiguous ways. The Philosophy, for the most part, represents childbearing women holistically as unique, multi-dimensional, respected, and empowered women. The language here pictures the woman not as an "object body" but a "lived body", using a "discourse of multidimensional being" not a "discourse of measurement" (Taylor, 2001, pp. 4, 5). In the context of this document, the quantitative OED definition of standard as "the authorized examplar of a unit of measure" and "as a permanent evidence of the legally prescribed magnitude of the unit" does not seem very applicable. However, perhaps the Philosophy of Midwifery Care in Ontario functions as a standard of excellence and as a kind of (figurative) "rallying point" for the new and distinctive profession of midwifery.

\section{Continuity of Care: Specifying How to Implement a Midwifery Ideal in the New Professional Context}

Along with informed choice, continuity of care is one of the key principles underlying the practice of midwifery in Ontario. Just as the concepts of "respect" and "shared responsibility" are open to interpretation, so too can the principle of continuity of care be defined and practised in diverse ways. However, unlike the fairly abstract treatment of the former concepts in the Philosophy, the CMO standard entitled Continuity of Care provides specific guidelines for midwives on how to implement this principle in practice. At the same time, though, this document intermingles-as a kind of countertext-less measurable, more qualitative descriptions of what constitutes continuity of care. This discursive mingling indicates the shifting, fragmented nature of the CMO meta-genre: rather than standardizing midwifery care in a clearly unified, consistent way, the CMO's institutional discourse reveals multiple sites of difference and points of slippage between conflicting versions of "reality" for this emerging profession.

At first glance, continuity of care would seem to be an issue that affects primarily the relationship between a midwife and the woman for whom she cares. Certainly, during the lobbying efforts to secure self-regulation, the Association of Ontario Midwives and supporters of midwifery presented continuity of care as one of the main reasons why the relationship between midwives and childbearing women was qualitatively different from the typically fragmented, discontinuous relationships between health professionals and women within the established healthcare system (Association of Ontario Midwives, 1986; Bergsagel, Burcher, \& Prokop, 1986). In the postlegislation context, however, the issue of continuity of care shifts from being primarily a question of value-that is, persuading the government and healthcare representatives that midwifery represents a distinctively valuable form of maternity care 
because it offers continuous care-to being more a question of procedure: how will this distinctive value be implemented in ways appropriate to the new realities of selfregulation within the framework of the main healthcare system? As the profession grows and as midwives are required to manage practices together (rather than working independently or in small groups of their own choosing as was typically the case prior to legislation), how can this standard of excellence be uniformly standardized across practice sites?

As we see in the CMO document, these questions of procedure are detailed mainly in terms of the working relationships among midwives who practise together. It prescribes in largely quantitative, measurable terms how the principle of continuity of care must be implemented uniformly by all registered members of the profession as they work together to care for their clients. The opening sentence of the document, for example, specifies that "Continuity of care is achieved when a relationship develops over time between a woman and a small group of no more than four midwives" (see Appendix B). Although this definition makes the relationship between the woman and the midwives central, it diffuses the traditional one-to-one intimacy between a woman and her midwife by permitting up to four midwives to be involved. Further, for the most part, the group of midwives does not together spend time developing a relationship with the woman receiving care; rather, the total time that they spend is divided among them as each meets separately with her. It is the cumulative total of each of these separate meeting times which constitutes the $\mathrm{CMO}$ requirement for continuity of care. ${ }^{\circ}$

From a rhetorical perspective, this regulatory document employs a quantitative whole-part representation of continuity of care and the professional relationships that this principle entails. As Perelman and Olbrechts-Tyteca (1971) explain, the division of the whole into its parts typically presumes that "by adding them [the parts] up the given whole may be reconstituted." Further, the division of the whole into its parts can function as a technique "to prove the existence of the wholes" (p. 235). In this sense, adding up each unit of time that each midwife spends with a woman reconstitutes the "whole" principle of continuity of care and simultaneously confirms the existence of this principle. In another sense, we can see the whole as the group who together enact the principle. In this case, each midwife constitutes one part of the whole. For the woman receiving care, the assumption seems to be that "what is true of the whole is true of the parts"(Perelman \& Olbrechts-Tyteca, 1971, p. 231): each midwife and each unit of time spent with the woman are presented as essentially similar, interchangeable parts. Professionalism, as Lay (2000) notes, "normalizes a practice so that practitioners and practices are uniform and cohesive" (p. 120). Notably, the cohesive whole referred to here is the team of midwives, not the midwives 
together with the woman. Continuity of care, as defined at the beginning of this $\mathrm{CMO}$ document, seems to involve the development of a close working relationship among the whole group of professionally similar midwives, but not between this group-as a whole-and the woman receiving care.

The limitation of the number of caregivers to four and the requirement that women and midwives get to know each other over time prescribe important contrasts to the deeply fragmented nature of maternity care in the dominant system. Nonetheless, the CMO definition of continuity of care does not, it would seem, quite capture the qualitative essence of this principle as praised by supporters of midwifery in the pre-legislative context and as suggested by the CMO Philosophy, where continuity of care is integrally associated with the development of an intimate relationship of trust between a woman and her midwife. In numerous testimonies by midwifery clients from the pre-legislative context, the ideal form of continuity of care is consistently figured as a relationship between one woman and one midwife, not between one woman and several midwives (see Bergsagel, Burcher, \& Prokop, 1986). In practical reality, of course, even in the pre-legislative context, it was not always possible for women to receive care from only one midwife throughout pregnancy, birth, and the post-partum period. In developing standards of practice for midwifery, therefore, the CMO must negotiate the tricky line between upholding the ideal of continuity of care and providing realistic guidelines for professional practice.

Presumably with the aim of providing such realistic guidelines, most of the document details quantitative standards for implementing continuity of care: for example, it provides numeric specification of midwives and hours on call, it divides the caregiving process into several discrete parts (e.g., "onset of pregnancy," "all trimesters," "labour," "birth," and "first weeks post-partum"), it mentions the importance of a "coordinated approach" and "regular meetings" among the group of midwives, and it classifies midwives in the group as "first," "second" and "other." At the same time, though, the document attempts to ensure that the qualitative ideal of the intimate, unique relationship between one woman and one midwife remains at least to some extent possible by requiring that the primary midwife in the group "make the time commitment necessary to develop a relationship of trust with the woman during pregnancy, to be able to provide safe, individualized care, fully support the woman during labour and birth and to provide comprehensive care to mother and newborn throughout the postpartum period" (our emphasis).

However, even though this passage emphasizes the development of a relationship of trust between the primary midwife and the childbearing woman, the document as a whole represents continuity of care primarily as an issue concerning how midwives work together as professional caregivers: "A consistent philosophy of care 
and coordinated approach to clinical practice should be maintained by caregivers working together, facilitated by regular meetings and peer review." These professional activities-although they are about the woman's course of care-do not include the woman as an active participant or decision-maker. As this document suggests, the professionalization of midwifery entails, on one hand, closer working relationships among colleague midwives and, on the other, greater distance between the client and the midwives who share her care (Sharpe, 1997, pp. 216, 226). The official redefinition of continuity of care in this CMO standard necessarily affects the qualitative uniqueness, personalization, and intimacy of the ideal relationship between an individual midwife and an individual woman. Despite the identification of one midwife as "primary" and the limitation of the number of midwives caring for any one woman to four, this document defines midwives as essentially interchangeable units. Does this mean that the women they care for are perceived as interchangeable units as well?

\section{Indications for Mandatory Discussion, Consultation and Transfer of Care: Reconfiguring Midwifery Care through the Screen of Biomedical Discourse}

The CMO standards function not only to render uniform the working relationships among midwives, they also, principally within the lengthy document entitled Indications for Mandatory Discussion, Consultation and Transfer of Care, standardize relationships among midwives and physicians. The standardization of the inter-professional relationship between midwives and physicians through this regulatory text further reconfigures the idealized relationship between the midwife and the woman as this is described in the Philosophy. In particular, it calls into question-more forcefully than the Contintity of Care document-the principles of decision-making as a process of shared responsibility between the midwife and the woman, and of the woman as the primary decision-maker in this relationship.

Politically, the question of how midwives interact professionally with physicians is a crucial one. The introduction of midwives as primary caregivers to the established healthcare system destabilizes the medical profession's domination of the system, at least in the domain of maternity care. Articulating precisely when midwives must consult with or transfer care to a physician helps to alleviate this sense of destabilization by providing reassurance that midwives are not permitted to operate completely independently nor overstep the boundaries of their legislated scope of practice as caregivers for normal pregnancy, labour, and post-partum period. Conversely, the Indications document helps to ensure that physicians will cooperate with midwives by providing specialist consultation and accepting transfers of care according to the standards it elaborates. Whereas the Continuity of Care standard focuses on 
structuring uniform intraprofessional relationships among individual midwives and across their diverse, local communities of practice, the Indications standard regulates interprofessional relationships; it spans the midwifery and medical communities, attempting to articulate a coherent, agreed-upon set of rules and categories that mediate the intersecting boundaries-the space of relationship-between these ideologically differentiated professional groups (Bowker \& Star, 2000, p. 13).

The document consists of two main, interrelated sections. The first part, which we focus on here, summarizes the midwife's responsibilities as a primary caregiver and defines three categories of interprofessional relationship: 1) mandatory discussion with another midwife or physician, 2) consultation with a physician, and 3) transfer of care to a physician. The second part of the document employs these three categories to list more than 100 risk conditions of pregnancy and childbirth which require midwives to engage in the three forms of interprofessional relationship with the medical community defined in the first part. ${ }^{\text {? }}$

A significant function of the first part of this document is to establish the midwife's professional identity and power relative to other healthcare professionals: she is described as a "primary caregiver" who has the responsibility and the authority to make decisions and to write, carry out, or delegate orders:

As a primary caregiver, the midwife together with the client is fully responsible for decision-making. The midwife is responsible for writing orders and carrying them out or delegating them in accordance with the standards of the College of Midwives. (see Appendix C)

Although the concept of shared responsibility receives here a token acknowledgment, we note how the phrase, "the midwife together with the client is fully responsible for decision-making" positions the midwife as the main agent with the woman included almost as an nonessential adjunct, a kind of parenthetical reference; as well, the use of the word "client" (rather than "woman" which is the term used in the Philosophy) emphasizes the professional distance between the midwife and the childbearing woman. The focus in this document on the interprofessional consultative relationship between midwives and physicians situates the childbearing woman not as someone in control of her course of care but, in conformity with standard medical approaches, as the site for "detection of an indication for consultation." In the version of reality presented here, midwives are primarily responsible to the larger healthcare system; they share the caring process not with their clients but with other healthcare professionals. Once the midwife has detected an indication for consultation, it is her 
responsibility "to initiate a discussion with or provide information to another midwife or physician, with whom the care is shared, in order to plan care appropriately" (our italics).

The lengthy definition for "Category 2: Consult with a physician" best illustrates the tension between the distinctive philosophical ideals of midwifery care, as articulated in the Philosophy document, and the practical / political realities of implementing them in the context of Ontario's mainstream healthcare system. Perhaps most strikingly, the CMO definition of consultation includes passages from the College of Physician and Surgeons of Ontario's own standard on consultation with midwives. ${ }^{8}$ This generic intertextuality (Berkenkotter, 2002) foregrounds the extent to which the domains of midwifery and of medicine are interconnected (however uneasily) through the consultative relationship, not only in healthcare practice but also at the metagenre level of negotiating the terms of the definition itself. Through this textual hybridity, the authoritative discourse of the medical profession literally becomes part of midwifery's new professional voice, a voice that sounds quite different from that heard in the Philosophy document.

In the incorporated CPSO passage, for instance, midwives are re-identified as "the referring professional" and their clients (or women) are re-subjected to the category of "patient." Physicians, meanwhile, retreat into the impersonalized, scientific, authoritative space of nominalization and unmarked human agency: "The consultation involves addressing the problem that led to the referral, an in-person assessment of the patient, and the prompt communication of the findings and recommendations to the patient and the referring professional" (2). By presenting the main action of consulting along with its embedded actions of assessing, communicating, finding, and recommending as static "things" or objects rather than as dynamic processes (Halliday \& Martin, 1993, pp. 131-132) and by omitting direct reference to the physician as the human agent who performs these actions, this sentence exemplifies what Haraway (1988) calls the masculinist-scientific "god trick of seeing everything from nowhere." This "conquering gaze," according to Haraway, situates the scientist as a disengaged and unmarked analyst of the object beneath his dominating eye (pp. 581582).

In the model of consultation prescribed here, the physician occupies an authoritative primary position not only as an expert knower, but also in the order or sequence of steps that the consultation process includes: first, the physician assesses the patient; then, "discussion can occur between the health professional and consultant regarding future patient care"; finally, "the midwife must discuss the consultant's recommendations with the client and ensure the client understands which health pro- 
fessional will have responsibility for primary care." This use of the loci of order affirms, as Perelman and Olbrecht-Tyteca (1971) explain, "the superiority of that which is earlier over that which is later" (p. 93).

As well, by quantitatively breaking down the process of consultation into discrete steps, this description produces a sense of clear boundaries between each stage and each relationship: the relationship between physician and patient dominates the first stage; the relationship between physician and midwife occupies the second stage; and the relationship between midwife and client informs the final stage. Only the relationship of the second stage, however, suggests the possibility of exchange or reciprocity between the participants through the cooperative professional activity of discussing together the patient's future care, although even in this generic situation, of course, the physician-as the specialist consultant-necessarily holds a more authoritative position than the midwife. In both the first and third stages, the relationships are even more obviously asymmetrical, positioning the patient/client as the passive recipient of, not an active participant in, the healthcare process: in the first case, the physician assesses the patient through the lens of scientific expertise; in the third case, although the midwife is directed to "discuss" the physician's recommendations with the woman, the main purpose of this discussion seems to be more to inform the woman of what has already been decided about her course of care (including the decision about which health professional will now have "primary responsibility") than to empower her to make informed decisions about her care.

In this model, then, decisions about what constitutes the most appropriate form of care take place without the client's involvement. The fundamental principles of informed choice and of the woman as primary decision maker seem to have faded to the background of the picture, with the woman now rendered as a more or less voiceless patient who functions as the site for detecting and assessing abnormalities through the screen of authoritative biomedical discourse (Taylor, 2001, p. 3).

\section{Conclusion}

As this analysis of just three of the regulatory documents from the CMO's Registrant's Binder indicates, the rhetorical forms and functions of this meta-genre are multiple, shifting, and-at times-ideologically incongruous. Exploring the rhetoricalideological conflicts (the competing versions of reality) that this meta-genre enacts as it seeks to regulate the professional relationships of midwives provides insight on the complex, uneasy trajectory of professionalization for midwifery in Ontario. Rhetorically, the three standards that we have examined are not "standardized" in the sense of representing and regulating midwives' professional relationships in consistent, uniform ways. Rather, when read in relation to each other, these three standards provide 
noticeably different interpretations and guidelines for midwives' professional relationships. Their rhetorical differences and incongruities at once reveal and help to shape the complex, ambiguous, and perhaps incompatible forms of relationship which the CMO directs registered midwives to develop with childbearing women, with other midwives, and with members of the dominant medical profession. In particular, the shift from the primarily qualitative and inspirational discourse of the Philosophy document to the increasingly more quantitative and biomedical / legalistic discourse of the Contimuity of Care and Indications documents draws our attention to the ways in which the seemingly non-standardizable yet central relationship of trust, mutual respect, and shared responsibility between the midwife and the childbearing woman is challenged and reconfigured by the demands of regulation within the dominant healthcare system.

\section{NOTES}

1 We are grateful for the support of the Social Sciences and Humanities Research Council of Canada in making this research program possible.

2 These provinces include Quebec, Ontario, Manitoba, Alberta, and British Columbia. The Northwest Territories, Yukon, Nunavut, and Newfoundland have provisions for midwifery practice in remote areas but they do not regulate midwives.

3 Written genres of professional communication for practising midwives regulated by the $\mathrm{CMO}$ would include, for example, some types of record-keeping, completing forms concerning registration/practice status, documentation concerning shared care with another health professional, etc. Other genres of professional communication, some of which are central to the standards discussed in this article and most of which are primarily oral, include for example facilitating the process of informed choice with a client, holding regular meetings and peer-review sessions with midwife colleagues, and consulting with other members of the healthcare system.

1 CMO policies "are developed to provide registered members, Council members, and staff with an overall plan respecting the general goals and accepted procedures of the College in such areas as development of standards or communication" (CMO, 2000b).

5 According to Shroff (1997), the midwifery goal of informed choice is "in direct contrast to 'informed consent' which is, at least, in practice, legal protection for physicians. 'Patients' are requested/required to sign legal consent and waiver forms before certain medical procedures are performed upon them. Unless 'patients' sign these forms, the procedure will not be carried out. In emergency situations when 'patients' are highly vulnerable, this kind of pressure may be viewed as coercive, particularly because physicians do not have a good track record for explaining procedures, based on the latest research, to ill people and their families" (pp. 18-19). 
${ }^{6}$ Further complicating this matter is the fact that, according to the government funding formula, midwives generally are paid based on the number of births they attend as a primary midwife not based on the number of hours spent providing continuity of care for individual women. The CMO does not collect data from midwives about continuity of care as the basis for decisions about their ongoing eligibility as registered midwives.

? Although we do not have the space here, this classificatory list warrants a detailed analysis in its own right, for example in terms of how it constructs a kind of "science of order" (Spoel, 1998) that normalizes the professional practices and knowledges of midwives through the hierarchical, biomedical classification of "abnormal" or "risk" conditions.

8 The CPSO document is entitled Clinical Practice Parameters and Standards for Consultation and Transfer of a Woman/Newborn in or from a Birth Centre Where Only Midwives Provide Primary Care, to a Physician/Health Facility.

9 In the portions of the text drafted by the CMO, however, the term "client" continues to be used.

\section{REFERENCES}

Association of Ontario Midwives (1986). Submission to the task force on the implementation of midwifery in Ontario. Toronto.

Barrington, E. (1984). The legalization of midwifery in Canada." Brief for the Health Committee of the National Action Committee on the Status of Women. Canada.

Bazerman, C. (1994). Systems of genres and the enactment of social intentions. In A. Freedman \& P. Medway (Eds.), Genre and the new rhetoric (pp. 79-101). London: Taylor and Francis.

Bergsagel, K., Burcher, B., \& Prokop, M. (1986). A brief presented to the task force on the implementation of midwifery in Ontario by the midwifery task force of Ontario. Toronto: Legislative Library of Ontario.

Berkenkotter, C. (2001). Genre Systems at Work: DSM-IV and Rhetorical Recontextualization in Psychotherapy Paperwork. Written Communication, 18 (3), 326-349.

Bowker, G. C. \& Star, S. L. (2000). Sorting things out: Classification and its consequences. Cambridge, Mass: MIT Press.

Burke, K. (1966). Language as symbolic action. Berkeley, CA: University of California Press. 
Coburn, D. (1993). State authority, medical dominance, and trends in the regulation of the health professions: the Ontario case. Social Science and Medicine, 37 (2), 129-138.

College of Midwives of Ontario (2000a). Continuity of care. Registrant's binder. Toronto.

College of Midwives of Ontario (2000b). Definition of terms. Registrant's binder. Toronto.

College of Midwives of Ontario (2000c). Indications for mandatory discussion, consultation, and transfer of care. Registrant's binder. Toronto.

College of Midwives of Ontario (2000d). Model of midwifery practice. Registrant's binder. Toronto.

College of Midwives of Ontario (2000e). Philosophy of midwifery care in Ontario. Registrant's binder. Toronto.

Davis-Floyd, R. (1996). The technocratic model of birth. In P. Wilson, A. Dally, \& C. R. King (Eds.), Childbirth: Changing ideas and practices in Britain and America- 1600 to present (pp. 247-276). New York: Garland Publishing.

Freedman, Aviva and Peter Medway, eds. Genre and the New Rhetoric. London: Taylor and Francis, 1994.

Giltrow, J. (2001). Meta-genre. The rhetoric and ideology of genre: Strategies for stability and change (pp. 187-205). Cresskill, NJ: Hampton Press.

Halliday, M. A. K., \& Martin, J.R. (1993). Writing science: Literacy and discursive power. Pittsbirgh: University of Pittsburgh Press.

Haraway, D. (1988). Situated knowledges: The science question in feminism and the privilege of partial perspective. Feminist Studies, 14 (3), 575-599.

Hughes, K. (1984). Midwifery in Canada. Ottawa: National Association of Women and the Law.

James, S. (1997). Regulation: Changing the face of midwifery? In F. Shroff (Ed.), The new midwifery: Reflections on renaissance and regulation (pp. 181-200). Toronto: Women's Press.

Lay, M. M. (2000). The rhetoric of midwifery: Gender, knowledge, and power. New Brunswick, NJ: Rutgers University Press. 
Kitzinger, S. (1988). Why women need midwives. In S. Kitzinger (Ed.), The midwife challenge (pp.1-20). London: Pandora Press.

Mason, J. (1990). The trouble with licensing midwives." Feminist Perspectives (1-31), Canadian Research Institute for the Advancement of Women.

Massey, E. (1993). By her own authority: The scope of midwifery practice under the Ontario midwifery act, 1991. Alberta Law Review 31 (2), 1-43.

Ontario (1991). Regulated health professions act, 1991. Statutes of Ontario, Chap. 18. Toronto: Legislative Library of Ontario.

Paré, A. (2002). Genre and identity: Individuals, institutions, and ideology. In Coe, R., Lingard, L., \& Teslenko, T. (Eds), The Rhetoric and ideology of genre (pp. 57-72). Cresskill, NJ: Hampton Press.

Perelman, C. H. \& Olbrechts-Tyteca, L. (1971). The new rhetoric: A treatise on argumentation. Notre Dame, IN: University of Notre Dame Press.

Rushing, B. (1993). Ideology in the reemergence of North American midwifery. Work and Occupations 20 (1), 46-67.

Sharpe, M. (1997). Ontario midwifery in transition: An exploration of midwives' perceptions of the impact of midwifery legislation in its first year. In F. Shroff (Ed.), The new midwifery: Reflections on renaissance and regulation (pp. 201244).

Shroff, F. (1997). Introduction : Midwifery - from rebellion to regulation. In F. Shroff (Ed.), The new midwifery: Reflections on renaissance and regulation (pp. 15-37). Toronto: Women's Press.

Spoel, P. (1998). Gilbert Austin's science of bodily rhetoric. Rhetoric Society Quarterly 28 (4), 5-27.

Taylor, D. (2001). Silenced partners: Epistemological and rhetorical barriers to interdisciplinary health care practice. Paper presented to the Canadian Society for the Study of Rhetoric, University of Laval, Quebec. 


\title{
APPENDIX A: PHILOSOPHY OF MIDWIFERY CARE IN ONTARIO (COMPLETE DOCUMENT)
}

\author{
COLLEGE OF MIDWIVES OF ONTARIO
}

N

ORDRE DES SAGES-FEMMES DE L'ONTAARIO

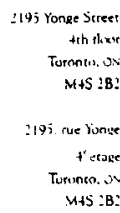

January 1994

\section{PHILOSOPHY OF MIDWIFERY CARE IN ONTARIO}

Midwifery care is based on a respect for pregnancy as a state of health and childbirth as a normal physiologic process and a profound event in a woman's life.

Midwifery care respects the diversity of women's needs and the variety of personal and cultural meanings which women, families and communities bring to the pregnancy, birth, and early parenting experience.

The maintenance and promotion of health throughout the childbearing cycle are central to midwifery care. Midwives focus on preventive care and the appropriate use of technology.

Care is continuous, personalized and non-authoritarian. It responds to a woman's social, emotional and cultural as well as physical needs.

Midwives respect the woman's right to choice of caregiver and place of birth in accordance with the Standards of Practice of the College of Midwives. Midwives are willing to attend birth in a variery of settings, including birth at home

Midwives encourage the woman to actively participate in her care throughout pregnancy, birh and postpartum period and make choices about the manner in which her care is provided.

Midwifery care includes education and counselling, enabling a woman to make informed choices.

Midwives promote decision-making as a shared responsibility, between the woman, her fanily (as defined by the woman) and her caregivers. The mother is recognized as the primary decision maker.

Midwives regard the interests of the woman and the ferus as compatible. They focus their care on the mother to obtain the best outcomes for the woman and her newbom.

Fundamental to midwifery care is the understanding that a woman's caregivers respect and support her so that she may give birth safely, with power and dignity. 


\title{
APPENDIX B: CONTINUITY OF CARE (PARTIAL DOCUMENT)
}

\author{
COLLEGE OF MIDWIVES OF ONTARIO \\ W \\ ORDRE DES SAGES-FEMMES DE L'ONTARIO
2105 tonge street
th ilikin
Tuninisicis
(Wt: $: B$ ?
$210 j$, ne lionise
thetse
Tirance. a \\ its: : : \\ January 1994
}

\begin{abstract}
Continuity of midwifery care is achieved when a relationship develops over time between a woman and a small group of no more than four midwives. Midwifery services must be made available by the same small group of caregivers from the onset of care (ideally, at the onset of pregnancy). during all trimesters, and throughout labour, birth and the first six weeks post-parturn. The midwifery practice must ensure there is 24 -hour on call avaitability of one of the group of midwives known to the woman. ${ }^{2}$
\end{abstract}

A consistent philosophy of care and coordinated approach to clinical practice should be maintained by caregivers working together, facilitated by regular meetings and peer review.

One of the group of midwives will be identified as the health professional responsible for coordinating the care and identifying who is responsible if she is not on call.' A second midwife should be identified as the midwife who weuld normally take over this role if the first midwife is unavailable. The practice should allow for opportunities for the woman to meet other midwives as appropriate to accommodate circumstances when they may be involved in her care. The midwife coordinating the woman's care and the second midwife must make the time commitment necessary to develop a relationship of trust with the woman during pregnancy, to be able to provide safe, individualized care, fully support the woman during labour and birth and to provide comprehensive care to mother and newbom throughout the postpartum period.

\footnotetext{
1 The standard for continuity of care does not restrict the number of midwives who may work together in a practice.

${ }^{3}$ Midwives from different practices may occassonally share the care of a client (to help cover hoildays, for example).

'Ths is consistent with Indications for Mandatory Discussion, Consultation and Transfer of Care.
} 


\title{
APPENDIX C: INDICATIONS FOR MANDATORY DISCUSSION, CONSULTATION AND TRANSFER OF CARE (PARTIAL DOCUMENT)
}

COLLEGE OF MIDWIVES OF ONTARIO

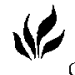

ORDRE DES SAGES-FEMMES DE L'ONTARIO

approved December 2, 1999

effective June 15,2000

\section{INDICATIONS FOR MANDATORY DISCUSSION, CONSULTATION AND TRANSFER OF CARE}

\begin{abstract}
As a primary caregiver, the midwife together with the client is fully responsible for decision-making. The midwife is responsible for writing orders and carrying them out or delegating them in accordance with the standards of the College of Midwives.

The midwife discusses care of a client, consults, or transfers primary care responsibility according to the Indications for Mandatory Discussion, Consultation and Transfer of Care.' The responsibility to consult with a family physician/general practitioner, obstetrician and/or specialist physician lies with the midwife. It is also the midwife's responsibility to initiate a consultation within an appropriate time after detection of an indication for consultation. The severity of the condition and the availability of a physician(s) will influence these decisions.

The informed choice agreement between the midwife and client should outline the extent of midwifery care, in order to make clients aware of the scope and limitations of midwifery care. The midwife should review the Indications for Mandatory Discussion. Consultation and Transfer of Care with the client.
\end{abstract}

\section{DEFINITIONS}

Category 1: Discuss with another midwife or with a physician

It is the midwife's responsibility to initiate a discussion with or provide information to another midwife or physician, with whom the care is shared, in order to plan care appropriately.

1 For a discussion of how this document is used to guide decisions about choice of birth place, see Indications for Planned Place of Birth.

Page 1 of 8 
College of Midwives of Ontario

Indications for Mandatory Disctession, Consultation and Transfer of Care

Approved December 2, 1999, Effective June 15, 2000

\section{Category 2: Consult with a physician}

It is the midwife's responsibility to initiate a consultation and to clearly communicate to the consultant that she is seeking a consultation. A consultation refers to the situation where a midwife, in light of her professional knowledge of the client and in accord with the standards of practice of the College of Midwives, or where another opinion is requested by the client, requests the opinion of a physician competent to give advice in this field. The midwife should expect that:

The consultation involves addressing the problem that led to the referral, an in-person assessment of the patient, and the prompt communication of the findings and recommendations to the patient and the referring professional.

Following the assessment of the patient by the consultant(s), discussion can occur between the health professional and consultant regarding future patient care. ${ }^{2}$

The consultation can involve the physician providing advice and information and/or providing therapy to the woman/newbor or prescribing therapy to the midwife for the woman/newborn.

Consultation must be documented by the midwife in her records in accord with the regulations of the College of Midwives.

After consultation with a physician, primary care of the client and responsibility for decision-making together with the client either:

a) continues with the midwife, or

b) is transferred to a physician.

Once a consultation has taken place and the consultant's findings, opinions and recommendations are communicated to the client and the midwife, the midwife must discuss the consultant's recommendations with the client and ensure the client understands which heal th professional will have responsibility for primary care.

2 "Clinical Practice Parameters and Standards for Consultation and Transfer of a Woman/Newbom in or from a Birth Centre Where Only Midwives Provide Primary Care, to a Physician/Health Facility, "College of Physicians and Surgeons of Ontario. December 23, 1993. 
College of Midwives of Ontano
Indications for Mandatory Discussion. Consultation and Transfer of Care
Approved December 2, 1999, Effective June 15,2000

Where urgency, distance or climatic conditions make an in-person consultation with a physician not possible, the midwife should seek advice from the physician by phone or other similar mears. The midwife should document this request for advice, in her records, in accord with the requirement of the College of Midwives and discuss with the client the advice received.

The consultant may be involved in, and responsible for, a discrete area of the client's care, with the midwife maintaining overall responsibility within her scope of practice. Areas of involvement in client care must be clearly agreed upon and documented by the midwife and the consultant.

The College of Midwives has agreed that:

One heaith professional has overall responsibility for a patient at any one time and the patient's care should be co-ordinated by that health professional whose identity should be clearly known to all of those involved and documented in the records of the referring health professional and consultant. Responsibility could be transferred temporarily to another health professional, or be shared between health professionals according to the patient's best interests and optimal care; however, transfer or sharing of care should only occur after discussion and agreement among patients, referring health professionals, and consultants. ${ }^{3}$

\section{Category 3: Transfer to a physician for primary care}

When primary care is transferred, permanently or temporarily, from the midwife to a physician, the physician, together with the client, assumes full responsibility for subsequent decision-making. When primary care is transferred to a physician, the midwife may provide supportive care ${ }^{4}$ within her scope of practice, in collaboration with the physician and the client.

3 "Clinical Practice Parameters and Standards for Consultation and Transfer of a Woman Newborm in or from a Birth Centre Where Only Midwives Provide Primary Care, to a Physiciard/Health Facility," College of Physicians and Surgeons of Ontano. December 23, 1993.

- Supportive care is defined in the Standard on Supportive Care.

Page 3 of 8 
College of Midwives of Ontario

Indications for Mandatory Discussion, Consultation and Transfer of Core

Approved December 2, 1999. Effective jume 15, 2000

INDICATIONS: Initial History and Physical Examination

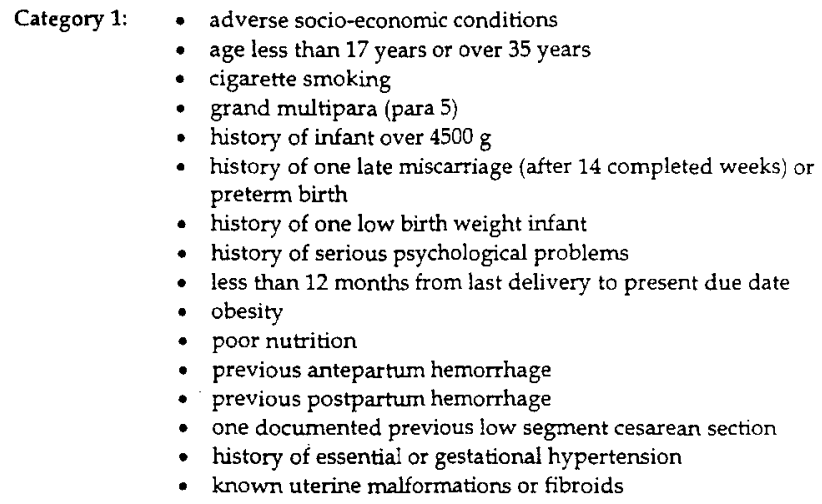

Category 2: - current medical conditions for example:5 cardiovascular disease, pulmonary disease, encocrine disorders, hepatic disease, neurologic disorders

- family history of genetic disorders

- family history of significant congenital anomalies

- history of cervical cerclage

- history of repeated spontaneous abortions

- history of more than one late miscarriage or preterm birth

- history of more than one low birth weight infant

- history of gestational hypertension with proteinuria and adverse sequelae

- history of significant medical illness

- previous myomectomy, hysterotomy or cesarean section other than one documented previous low segment cesarean section

- previous neonatal mortality or stillbirth

- rubella during first trimester of pregnancy

5 Refer to Guidelines to Antepartum Consultations for Clients of Midwioes to Anaesthesia, July 1996.

Page 4 of 8 
College of Midwives of Ontario

Indicuttons for Mandatory Discussion, Consultation and Transfer of Care

Approved December 2, 1999, Effective iune 15, 2000

- significant use of drugs or alcohol

- age less than 14 years

Category 3: - any serious medical condition, for example: cardiac or renal disease with failure or insulin dependent diabetes mellitus

\section{INDICATIONS: Prenatal Care}

Category 1: - presentation other than cephalic at 36 completed weeks

- no prenatal care before 28 completed weeks

- uncertain expected date of delivery

- uncomplicated spontaneous abortion less than 12 completed weeks
Category 2: - anemia (unresponsive to therapy)
- documented post term pregnancy (42 completed weeks)
- fetal anomaly
- inappropriate uterine growth
- medical conditions arising during prenatal care, for example endocrine disorders, hypertension, renal disease, suspected significant infection, hyperemesis
- placenta previa without bleeding
- polyhydramnios or oligohydramnios
- gestational hypertension
- isoimmunization
- serious psychological problems ${ }^{6}$
- sexually transmitted disease
- twins
- vaginal bleeding other than transient spotting
- presentation other than cephalic, urresponsive to therapy, at 38 completed weeks

\footnotetext{
- Notwithstanding the requirement for consultation with a physician, consultation may be with another copropriate heal th care professional; for example, a mental heal th worker.
}

Page 5 of 8 